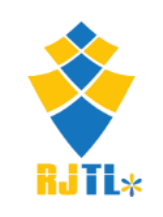

Available online at https://www.rjtl.org

Volume: 1, Issue: 1, 1-10, 2020

ISSN: $2708-3632$

DOI: https://doi.org/10.46590/rjtl.2020.010101

\title{
Extraction, Screening and Spectral Characterization of Tannins from Acacia Xanthophloea (Fever Tree) Bark
}

\author{
Ramesh Duraisamy*, Tesema Shuge, Bezawit Worku, Abiyu Kerebo Berekete and \\ Karthikeyan M.Ramasamy
}

Department of Chemistry Industrial Chemistry), Arba Minch University, Ethiopia

\section{Paper History:}

Received : March. 2020

Accepted : April 2020

Published : May 2020

Corresponding Author:

Ramesh Duraisamy

drrameshmcas@gmail.com

\begin{abstract}
Identifying studied sample acacia species selected and collected from Bekele Molla Hotel Avenue, Chamo Kebele, Arba Minch under convenient random sampling method. Tannins extracted using the solvents such as water (at $60 \& 90^{\circ} \mathrm{C}$ ), methanol $\left(\right.$ at $90^{\circ} \mathrm{C}$ ) and its 1:1 mixture (at $90^{\circ} \mathrm{C}$ ) by employing Soxhlet extraction. Extracted crude tannins was separated and purified under vacuum distillation. The photochemical screening and quantitative determinations of sample carried out. Furthermore, the sample of tannins characterized by employing U-visible and FTIR spectroscopic studies. Methonalic extract consist moisture content and \% yield about $17.86 \pm 0.51 \%$ and $52.55 \%$. The results of Uv-visible and FTIR spectroscopic studies were supporting that the sample of Acacia xanthophloea has tannins and flavonoids. Thus, this study reveals and confirmed that the methanol is more suitable solvent for extraction of tannins over than water.
\end{abstract}

Keywords: Acacia xanthophloea, Fever Tree, FTIR spectroscopy, Methanol, UV-visible

Citation: Ramesh Duraisamy, Tesema Shuge, Bezawit Worku, Abiyu Kerebo Berekete and Karthikeyan M.Ramasamy, Extraction, Screening and Spectral Characterization of Tannins from Acacia Xanthophloea (Fever Tree) Bark, Research Journal of Textile and Leather, 1(1), 1-10, 2020.

\section{BACKGROUND OF THE STUDY}

Raw skin/hide is a stuff which is simply degradable, but through the serious step of processing including tanning of raw skin/hide changed into physico-chemically stable leather, even that exposed into a series of different processes. Upon the processing, where the skin becomes stabilized and its hydrothermal strength improved are communally called as tanning $[1,2]$. Ancient day onwards leather processing from animal hides undergone; but, till now the modern leather processing uses chromium for tanning of the skin. Chrome tanning is harmful to the environment; due to discharging off some harmful chrome salts they have produced with little skill and very often mass products during tanning process. Chrome tanning is by far the most commonly used method for tanning of leathers and shoe upper leathers. The advantages of chrome tanning materials over the other commercially available tanning materials are the

high speeds of protein fixation with low chemical costs, and excellent hide preservation but products used in processing fails about the impact on the environment. Further, the characteristics of an industrial wastewater stream depend to a large extent on the type of products being produced and treatment of pollutants is also on the added expensive for the industry [3]. Thus, avoid the environmental pollution and the strict environmental regulations implemented by the developed and developing nations. The leather industries and researchers forced to find alternative tanning materials from natural resources. Hence, the researchers undertaken the series of researches and found the plants (phyto) based tanning materials called bio-tannins or vegetable tannin that used successfully in many researches and proved as alternative to the 
chromium that used in chrome tanning in leather industries [3]. The corresponding tanning of skin/hide that transformed in to leather by undergone with bio-tannins called as bio-tanning or vegetable tanning (also termed as phytotanning).

Tannins (hydrolysable and non-hydrolysable) have capability to make linking with skinproteins (collagen) form compact and hydrological steady product called leather. Tannins are well-known ingredient in the process of tanning of leather. According to the literatures stated [4-8]. Tanbark from oak, Mimosa, Birch, Hemlock, Chestnut, okra, Fir bark and Quebracho (have catechol) and Oak bark has both types of tannins. All the phyto-tannins have traditionally used as the primary source of tannery tannin, and account for $90 \%$ of the world's leather production.

Phyto-tanning engage treats the hides and skins with vegetation and bark restrain tannins. Tannins are polyphenolic compounds with molecular weight of 500-20,000, makes precipitate of proteins and alkaloids. Although the tannins make crosslink with collagen and it's develop leather. But, quality of leather affected (by type and sources of tannins) during pre-tanning and post-tanning processes, and corresponding tanned matters can influence to the value of leather.

The type of tanning materials used in leather production affects the physical characteristics of the leather which produced from the same origin. Although, phyto-tanned leathers offers some physico-mechanical benefits to the finished leather $[9,10]$.

Skins and hides tanned with phyto-tannins from different sources of tanning materials gives leathers with different physical properties. The physical properties of final leather find its uses on preparation of the product. All the vegetable tanned leathers for use in making leather products must meet the minimum recommended standard to make satisfactory products of good quality [11]. Ekaterini Malea et al. [12] extracted the tannins from four native and foreign woody plant parts such as leaves, bark, stem and roots studied and characterized by influences of different parameters.

Phyto-tannins that almost used to tan any type of hide and skins of cows, calves, buffalos, goats, snakes, sheep, pigs, ostriches, and stingrays [13]. The reported results shown, the plant-based tannins are better alternative method of tanning to chrome tonnage because of environmental friendly than chrome tanning, low-cost and ease to apply in to diverse kinds of leather.

Unlike chrome tanning, vegetable tanning can take up to at least 3-4 days to produce a piece of dyed leather. But, it is environmentally friendly and recyclable, only natural ingredients could be used when dying the hides, better performance leather might be achieved often healthier than chrome tanning [6-12]. In this concern, Acacia xanthophloea (A.xanthophloea) is one of the most important vegetable tanning material, which suggesting alternative bio-tannin raw material for getting finished leather. This variety of acacia tree (shown in Figure 1) is easy accessible in study area.

Despite that the widely available local resources like A.xanthophloea like plant bio-materials and vegetable tanning remains underdeveloped and neglected method of leather tanning in Africa. But it's a very important to health concern, to cut economic expenditure and reduces the hazardous to existing life and environment.

In this context, the current study focused the characterization of bio-tannins that extracted from A.xanthophloea bark. These kinds of biotannins are mainly useful raw materials into leather industries as vegetable tanning that are also used as natural ingredients available around us. Furthermore, vegetable tanning is arguably more sustainable and ecologically friendly than conventional leather tanning methods, especially chrome tanning method.

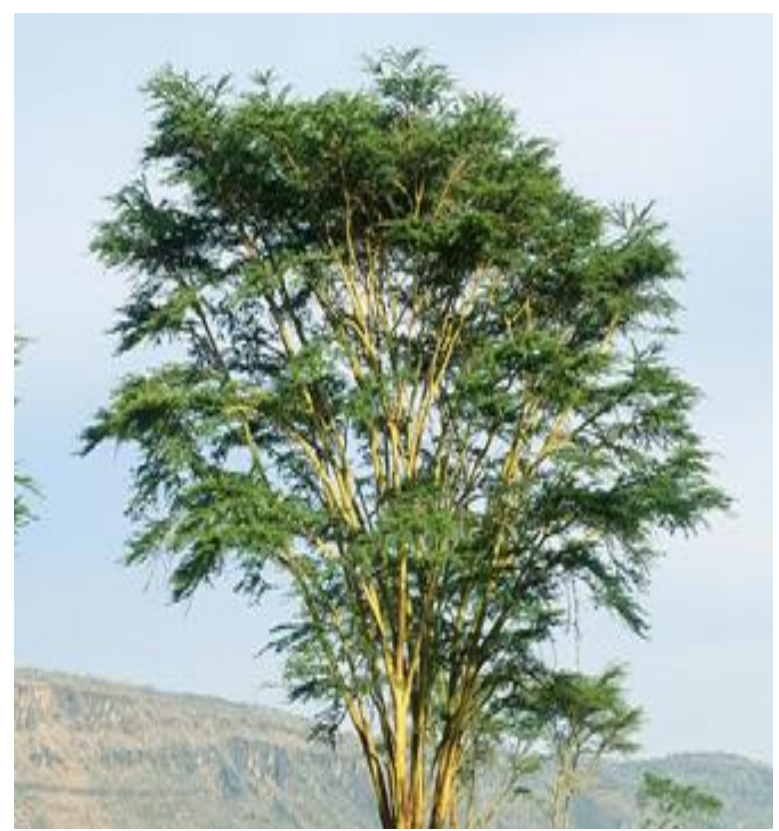

Figure 1. Photograph of Acacia xanthophloea tree 


\section{EXPERIMENTAL DETAILS}

\subsection{Preparation of Acacia Xanthophloea Bark Powder}

Matured bark part (Figure 2) of A.xanthophloea was collected under convenient random sampling method from Bekele Molla, Chamo Kebele, Arba Minch. The collected samples were pre-treated as by cleaned and washed well with water and left for air dry under room temperature and dried in sunlight. The pre-treated samples were grinded by using laboratory analytical mill grinder and obtained a crude powder (Figure 3). Then the powdered plant samples were preserved under moisture free atmosphere for further use to extract the tannins under room temperature.

\subsection{Preparation of Crude Tannin Extract}

Bulk collections of bark samples (dried in air) grounded well in a Lab mill and sieved through $2 \mathrm{~mm}$ sized sieves. About $30 \mathrm{~g}$ part of the sample placed in a $250 \mathrm{~mL}$ thimbles of Soxhlet apparatus (Figure 4) with $150 \mathrm{~mL}$ of distilled water, another (30 g ) part of the sample with $80 \%$ methanol, and a third part $(30 \mathrm{~g})$ sample placed with 1:1 methanol and water mixture $(250 \mathrm{~mL})$ each. The solution subjected to heat for 4 hours with constant temperatures at $30^{\circ} \mathrm{C}, 60^{\circ} \mathrm{C}$ and $90^{\circ} \mathrm{C}$ for extraction of tannins and for other portions carried out at $90^{\circ} \mathrm{C}$ for 4 hours. All the samples filtered (using Whatman No.1 filter paper, $18.5 \mathrm{~cm}$ disc) and the remaining stuff washed and separated with more solvent. Extracts had transferred in to a tarred, volumetric flask and concentrated by employing vacuüm rotary evaporator (Figure 5), obtained concentrated extracts. Samples of extract desiccated in a vacuüm hot air-oven at $60^{\circ} \mathrm{C}$ [14], achieved bright reddish-orange solid/powder (shown in Figure 6) that used for further experiments.

\subsection{Characterization of Acacia xanthophloea Tannins}

Characterization of crude extract done by determination of moisture content, percentage yield, types of tannins (condensed type or hydrolyzed), amount of tannin or total phenol, total flavonoids, total solids, as well as color of the tannin present in the selected plant of A.xanthophloea. In order to estimate the composition of tannins of the sample, it's characterized through UV-visible and FTIR spectroscopic studies, and compared the results with reported literatures of tannins and related phenolics.

\subsubsection{Determination of Percentage Yield of Extract}

Extract of each samples (3 samples) loaded on a pre-weighed beaker, and kept in an oven about $105^{\circ} \mathrm{C}$ until reached constant weight, cooled to room temperature; make sure free from any trace of moisture by employing desiccators containing $\mathrm{CaCl}_{2}$ and weighed the sample again.

The extract of each sample allowed and reacting efficiently with $20 \mathrm{~mL}$ of $1: 1 \mathrm{v} / \mathrm{v}$ solvent mixture of con. $\mathrm{HCl}$ and formalin $(1: 1 \mathrm{v} / \mathrm{v})$ for 4 hours, that enable the solute to dissolve in it. The precipitated solution filtered through a preweighed sintered glass filter, washed then with warm water. Obtained precipitate air-dried to $10 \%$ moisture and reweighed. Percentage yield of sample calculated using the formula [15].

$\%$ yield of sample $=\frac{\mathrm{W}_{2}-\mathrm{W}_{1}}{-------\mathrm{X}_{\mathrm{o}}}$

Where,

$$
\begin{aligned}
& \mathrm{W}_{\mathrm{o}} \text { - Initial weight of sample } \\
& \mathrm{W}_{1} \text { - Weight of empty beaker } \\
& \mathrm{W}_{2} \text { - Weight of the extract + beaker after } \\
& \text { dried the sample }
\end{aligned}
$$

\subsubsection{Moisture Content}

About $5 \mathrm{~g}$ of finely grounded extracted tannins of each sample placed in a pre-weighed crucible and set aside back in hot air-oven at $90^{\circ} \mathrm{C}$ up to 3-4 hours (achieved stable weight), slow down the temperature of the crucible in to room atmosphere by keeping in desiccators and reweighed. Then, moisture content was estimated from the weight loss of the sample [15]:

$$
\% \text { moisture }=\frac{\text { Loss in weight }\left(\mathrm{w}_{1}-\mathrm{w}_{2}\right)}{\text { Weight of sample }\left(\mathrm{w}_{1}\right)}
$$

Where,

$\mathrm{W}_{1}$ - Weight (g) of the sample taken for test $\mathrm{W}_{2}$ - Weight ( $\mathrm{g}$ ) of residue left after drying

\subsubsection{Identification of Tannins Using $\mathrm{FeCl}_{3}$}

About 5 drops of alc. $\mathrm{FeCl}_{3}$ is added into $1 \mathrm{~mL}$ of the aqueous sample taken in a test tube. Green to black precipitate might be appears, it reveals the presence of tannins according to literature [16].

\subsubsection{Test with Ferrous Sulphate Solution}

Accurately measured part $(1 \mathrm{~mL})$ of the sample extract taken place in a test tube and $0.1 \% \mathrm{FeSO}_{4}$ $(2 \mathrm{~mL})$ and $0.5 \%$ sodium potassium tartarate 


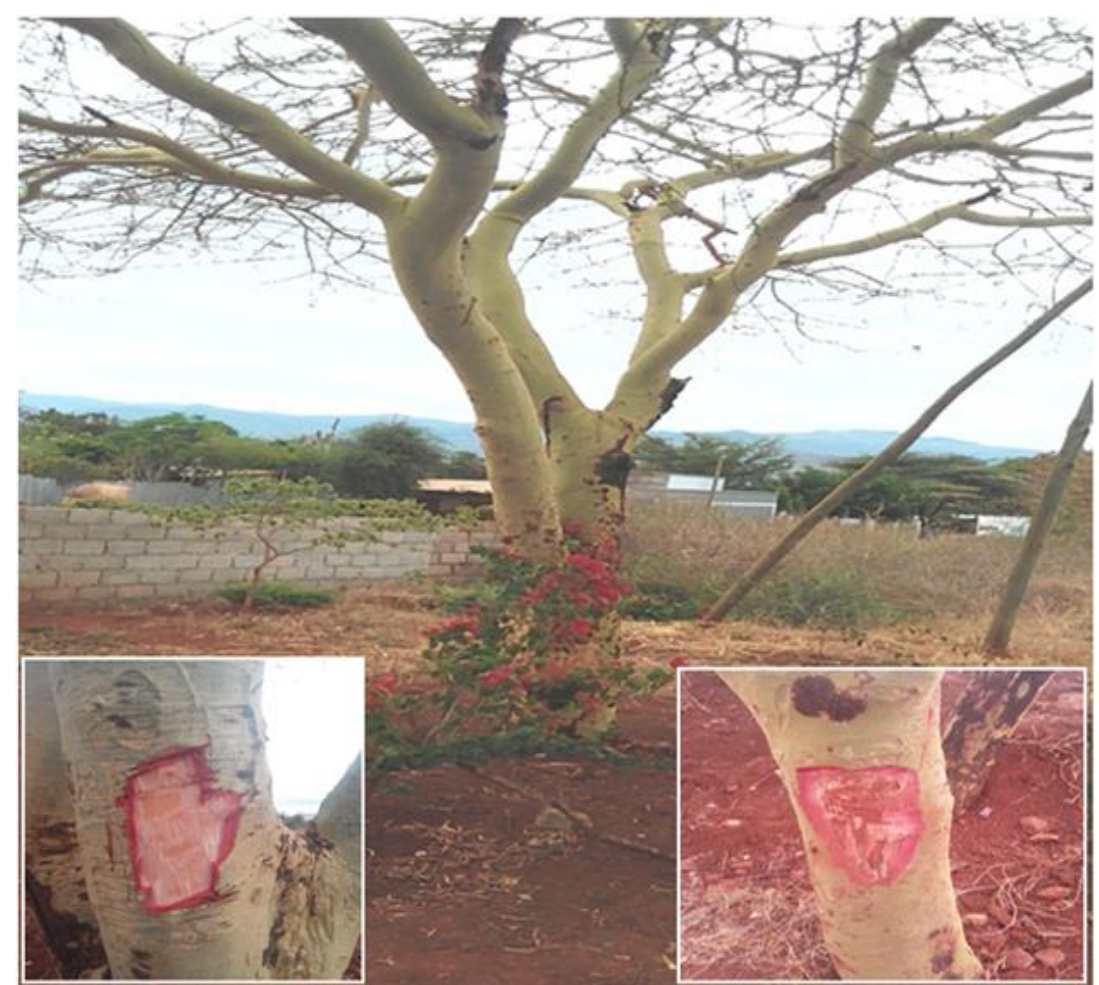

Figure 2. Photograph of Acacia xanthophloea tree and bark part

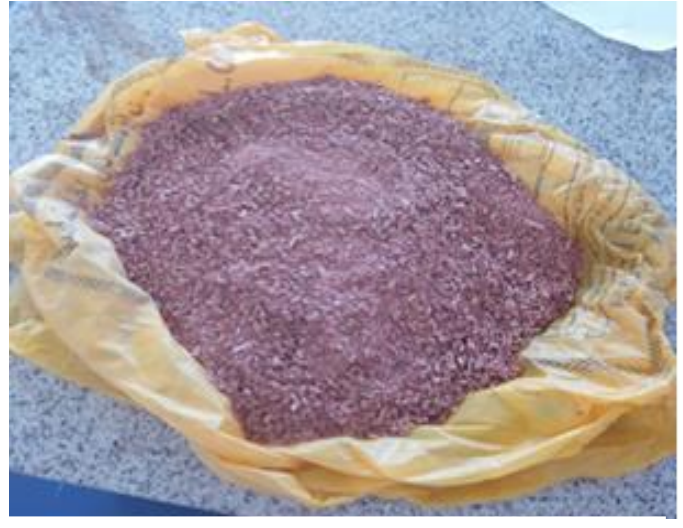

Figure 3. Powdered crude extract of A. xanthophloea

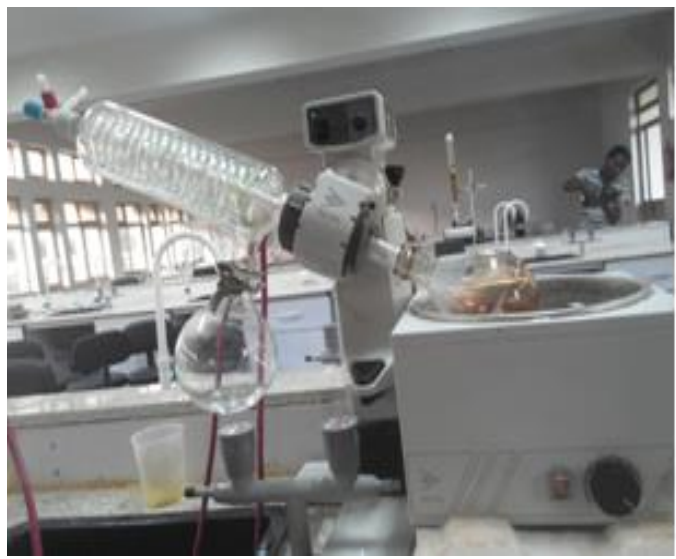

Figure 5. Rotary evaporator used for the A. xanthophloea tannin extraction

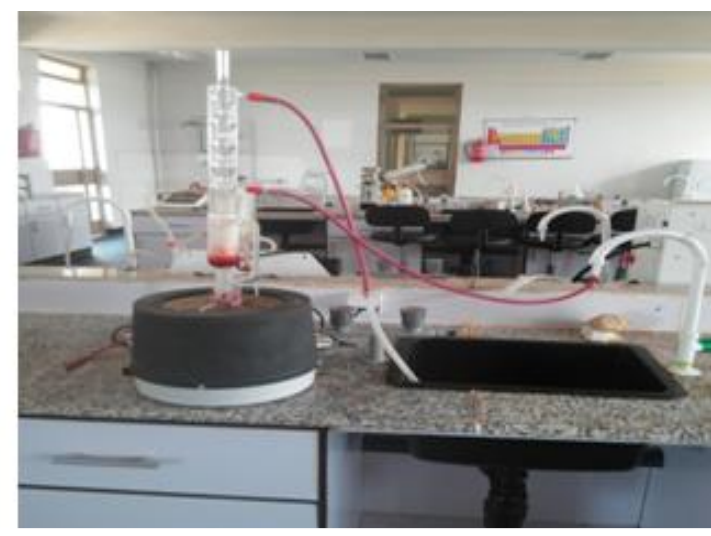

Figure 4. Soxhlet apparatus used for the extraction of A.xanthophloea tannins

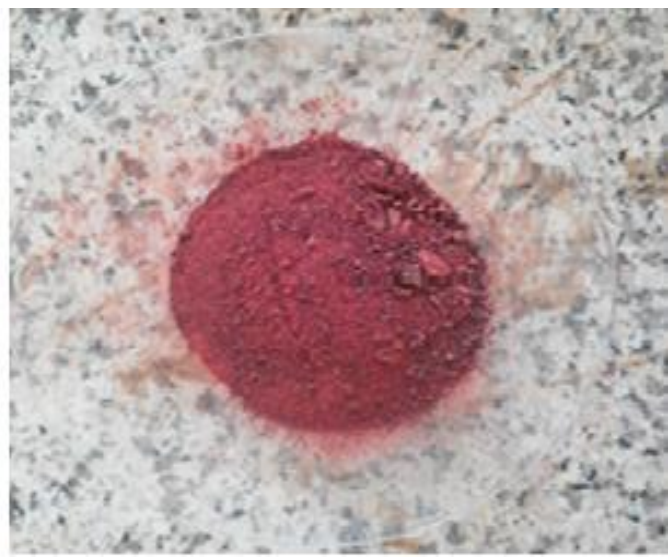

Figure 6. Extracted, powdered \& crystallized A. xanthophloea tannins 
added into the test tube containing sample. Appearance of violet color indicates presence of tannins as evident through reported [17].

\subsubsection{UV-Visible spectral Analysis of Acacia xanthophloea Tannins}

Exactly weighed $(250 \mathrm{mg}$ ) measure of sample powder dissolved in distilled water $(50 \mathrm{~mL})$ and filtered it. Then, analyze filtrate through Uv-visible spectroscopy (SPECORD 50 PLUS, Germany) at a ranged 190 to $600 \mathrm{~nm}$ at an interval of $20 \mathrm{~nm}$ against water blank, and detected the characteristic wavelength of the studied plant extract.

\subsubsection{FTIR Spectroscopy Analysis of Acacia xanthophloea Tannins}

The dried grinded fine powder of samples mixed (1:100 ratio) with $\mathrm{KBr}$ (FTIR grade) and hard-pressed in to a pellet. It's kept instantly into the sample tube of Spectrum 65 FTIR (Perkin Elmer) and scanned in the range 4000-400 $\mathrm{cm}^{-1}$ at room temperature. The spectrum of the samples and its data is obtained by using essential FTIR software. Obtained spectral data and the functional groups detected that compared with the earlier reported studies.

\section{RESULT AND DISCUSSION}

\subsection{Determination of Moisture Content}

Moisture content analysis gives the information of moisture available in the given sample of A.xanthophloea bark. The result of moisture content of the sample is $17.86 \pm 0.51$ $\%$ by weight of the sample and comparison of the moisture content on triplicate measurement is closure and standard deviation become \pm 0.51 , which shows the accuracy of measurement (shown in Table 1). Thus, the sample of A.xanthophloea have greater amount of phyto-chemicals with less moisture content.

Table 1. Determination of moisture content on sample Acacia xanthophloea

\begin{tabular}{llll}
\hline Trials & $\begin{array}{l}\text { Weight of } \\
\text { extract } \\
\text { before } \\
\text { drying }(\mathrm{g})\end{array}$ & $\begin{array}{l}\text { Weight of } \\
\text { extract } \\
\text { after } \\
\text { drying }(\mathrm{g})\end{array}$ & $\begin{array}{l}\text { Moisture } \\
\text { content }(\%)\end{array}$ \\
\hline 1 & 5.21 & 4.275 & 17.95 \\
2 & 5.072 & 4.194 & 17.31 \\
3 & 5.152 & 4.208 & 18.32 \\
\hline \multicolumn{2}{l}{ Average $\pm \mathrm{SD}(\mathrm{g})$} & & $17.86 \pm 0.51$ \\
\hline
\end{tabular}

\subsection{Estimation of \% Yield of Tannin Extract}

In this study, the soxhlet extraction of tannin from A.xantophloea bark carried out by employing two solvents such as water and methanol and its mixture $(1: 1)$ with in a different temperature $\left(30-60^{\circ} \mathrm{C}\right.$ for water; $90^{\circ} \mathrm{C}$ for water and mixture of solvents). After the extraction process the solvents removed by two techniques as water removed by evaporation by using hot plates along with direct heat since methanol removed by using rotary evaporator. Results of extraction were given in Table 2 . While comparing the results of \% tannin extraction, aqueous extract at $90^{\circ} \mathrm{C}$ has greater yield $(49.22 \%)$ than extraction of tannins at 30 and $60^{\circ} \mathrm{C}$ (shown in Table 2). Also, \% yield of tannin extraction compared upon different solvents, the results were reveals that the methanol used as a extracting solvent that extract has the greater amount of tannins $(52.55 \%$ of yield) from the sample of A.xanthophloea than other solvents such as water and its mixture (shown in Table 2). This is due to the solvent that had superior percentage of methanol; even though tannins are well-known highly water-soluble. Hence, water proved as an ineffective extracting solvent for tannins. This is due to the formation of tannin-protein complexes. The efficiency of methanol as a solvent used for extracting of tannin might be due to it being an organic polar solvent. The methanol polarity makes it able to have strong interactions with polar substances like tannin [18].

From this study, bark of A.xanthophloea is identified as a source of vegetable tanning material. Although the local tanners are not aware of the tannin content, and this study suggests that the barks which produces deep colored liquor has more tanning chemicals compared to other plants parts according to Smith et al. [19]. They also found that the barks from acacia species have more tannin content than other plants. A.xanthophloea tannins has not been used in leather production but used as medicinal plants.

This study found that the percentage of tannins content in methanol, water at $30^{\circ} \mathrm{C}, 60^{\circ} \mathrm{C}$ and $90^{\circ} \mathrm{C}$ and mixture of water and methanol of A.xanthophloea bark as $52.55 \%, 37.22 \%$, $39.22 \%, 49.22 \%$ and $45.01 \%$ respectively. The findings of this study differed slightly with findings from other studies elsewhere. 
Table 2. Yield of Acacia xanthophloea Tannin Extract

\begin{tabular}{|c|c|c|c|c|c|c|}
\hline \multirow[t]{2}{*}{ Solvents } & \multirow[t]{2}{*}{ Temperature $\left({ }^{\circ} \mathrm{C}\right)$} & \multicolumn{3}{|c|}{$\begin{array}{l}\text { Amount of tannins extracted } \\
\qquad(\mathrm{g} / 30 \mathrm{~g} \text { of sample })\end{array}$} & \multirow[t]{2}{*}{$\begin{array}{c}\text { Average } \\
(\mathrm{X} \pm \mathrm{SD})(\mathrm{g})\end{array}$} & \multirow[t]{2}{*}{$\begin{array}{c}\% \text { of } \\
\text { extraction }\end{array}$} \\
\hline & & Trial-1 & Trial-2 & Trial-3 & & \\
\hline \multirow{3}{*}{ Water } & 30 & 10.2 & 11.2 & 12.1 & $11.166 \pm 0.95$ & 37.22 \\
\hline & 60 & 10.7 & 11.6 & 13.0 & $11.766 \pm 1.16$ & 39.22 \\
\hline & 90 & 13.6 & 12.6 & 18.1 & $14.766 \pm 2.93$ & 49.22 \\
\hline Methanol & 90 & 19.2 & 17.1 & 11.0 & $15.766 \pm 4.26$ & 52.55 \\
\hline Methanol \& Water $(1: 1)$ & 90 & 13.01 & 13.9 & 13.6 & $13.503 \pm 0.45$ & 45.01 \\
\hline
\end{tabular}

For example, a study has reported by Nundkum and Ojewole [20] in South Africa have found A.xanthophloea barks would contain around $50 \%$ condensed tannins in methanol solvent and $36 \%$ in water solvent extracted. The differences in the tannin content from the various studies found that might be due to the variations in the environmental factors, high temperature, water stress, extremes light intensities and poor soil quality are known to increase the tannins contents in plants. The tannins contents also vary with the bark thickness, age of the trees and from the base of the trunk upwards with the branch having low tannin contents [21].

Haroun et al. [22] reported that the quantitative data revealed that the barks of the trees species have more than $35 \%$ tannins required for commercial extractions, that's confirmed from the study, methanol could be used as more efficient extraction solvent than water and methanol -water mixtures (Table 2) in terms of the mass of tannin substance extracted from a given mass of studies sample A.xantophloea.

\subsection{Tannin Screening Test}

Tannin screening test of the extracted samples carried out and the results show that presence of some of the polyphenolic phyto-chemicals as per literature stated [23]. The noticed observation is given in Table.3.

Table 3. Chemical Tests of the extracted samples of Acacia xanthophloea

\begin{tabular}{llll}
\hline Test & $\begin{array}{l}\text { Water } \\
\text { extract }\end{array}$ & $\begin{array}{l}\text { Methanolic } \\
\text { extract }\end{array}$ & $\begin{array}{l}\text { Mixture of } \\
\text { methanol }+ \\
\text { water }\end{array}$ \\
\hline $\begin{array}{l}\text { Ferric } \\
\text { chloride }\end{array}$ & positive & positive & positive \\
$\begin{array}{l}\text { Ferrous } \\
\text { sulphate } \\
\text { with sodium } \\
\text { tartarate }\end{array}$ & positive & positive & positive \\
\hline
\end{tabular}

The results shows that while undergone the sample of extract with chemical tests does obtained positive results, reveals that presence of tannins in a studied sample of extract. Also the extracting solvents such as water, methanol and its mixture as well confirmed to extract the tannins from bark of A.xanthophloea.

\subsection{Spectral Studies of Acacia Xanthophloea Tannins}

\subsubsection{UV-Visible Spectroscopic Study}

\subsubsection{Characterization of Aqueous Tannins Extract on Temperature}

The UV-visible absorption spectrum of the aqueous tannin extracts that obtained upon different temperatures shown in Figure 7. The present study reveals the major bands which were appears in the range of $270-320 \mathrm{~nm}$ with the absorbance about 0.39 - 1.94. The spectrum for concern polyphenols typically lay in the range 230-290nm that reported [24]. Kajdzanoska et al. [25] revealed that the absorption maxima at 280 show flavonols. Sisa et al. [26] reported that the absorption maxima at 255, 280, 330 and $350 \mathrm{~nm}$ shown the presence of flavone ring system. Thus, resulting UV-visible spectral study authenticate the existence of tannins and flavonoid ring system on aqueous extract of studied A.xanthophloea at all range of extraction temperatures between $30^{\circ} \mathrm{C}-90^{\circ} \mathrm{C}$.

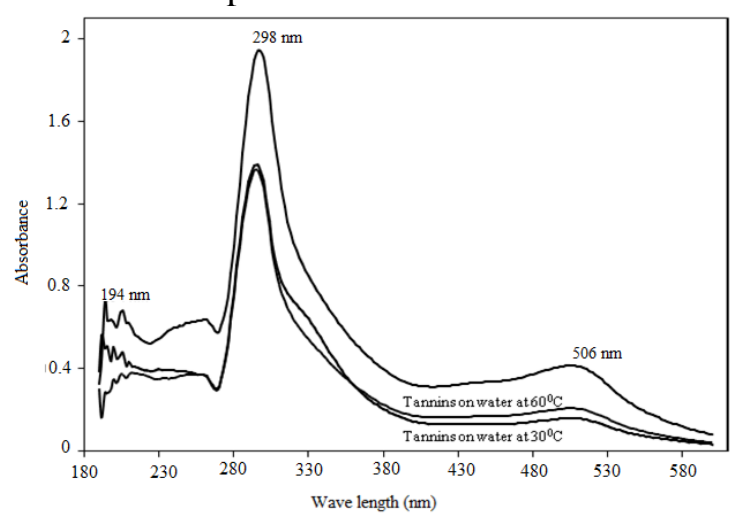

Figure 7. UV-visible spectrum of Acacia xanthopholoea tannin on water at $30-90^{\circ} \mathrm{C}$

Furthermore, compare the UV-visible spectrum of water extract samples upon $30^{\circ} \mathrm{C}$ and $90^{\circ} \mathrm{C}$ are almost similar beyond the 
wavelength of $260 \mathrm{~nm}$ then later slightly lower absorption of the spectrum of lower temperature $\left(30^{\circ} \mathrm{C}\right)$ fraction of extract. But, at lower range of wavelengths the spectrum of tannin sample (extract at $30^{\circ} \mathrm{C}$ ) has higher absorption, due to may decompose some phyto-chemicals upon rising the temperature moderately but not at high temperature close to boiling point of water (shown in Figure 7). Also, extracted the tannins from A. xanthopholoea at $90^{\circ} \mathrm{C}$ has greater yield that confirms the maximum absorption at all ranges of wavelength and existing the shifting of $\lambda \max$ towards higher wavelength called bathochromic (red) shift. But in all the cases there is no change does takes place at $506 \mathrm{~nm}$, show that the corresponding phytochemical persist consistently (Figure 7) without decomposition at all temperature ranges.

\subsubsection{Effect of Solvent for Tannins Extraction Using UV-Visible Spectra}

UV-visible spectrums of tannins extracted from A.xanthophloea by employing different solvents presented in Figure 8. This reveals that appearance of peak in respective wavelengths is similar like the peak of spectrum corresponds to the extracted samples on aqueous medium. The spectrum of the extracts compared with standards when using different solvents such as methanol, water and its 1:1 mixture that shows peak maxima ranged at $292-296 \mathrm{~nm}$ by decreasing absorption of respective $\lambda_{\max }$ peak, this trend followed throughout the range of wavelength. It shows that extraction of tannins in water has largest yield that get decreases by employing the extraction with methanol and mixed methanol does exists hypsochromic (blue shift) and hypochromic shifts (decrement of absorption) that shown in Figure 8. Absorption peak maxima around 280-296 nm and 252-262 nm and compared with standards of polyphenols show presence of polyphenolic acids (shown in Table 4), and catechin (Flavan-3-ols) considered as a monomer of condensed tannins as reported literature [27]. The results revealed that the water may consider as an appropriate solvent than methanol and its mixture.

\subsubsection{FTIR Spectroscopic Study}

FTIR characterization of the presently studied samples and its corresponding peak picking spectrums described in Figures 9 and 10. The study revealed that the strong absorption band between $3700-3100 \mathrm{~cm}^{-1}$ with a broad \& wellbuilt band. It shows, presence of $-\mathrm{OH}$ stretching and owing to broad variety of hydrogen bonding between hydroxyl groups, which is well agreed with literature [28] and showing availability of phenols and alcohols. Band at $2926 \mathrm{~cm}^{-1}$ and a little shoulder around $2850 \mathrm{~cm}^{-1}$ correlated with symmetric and antisymmetric $\mathrm{CH}$ - stretching's of $\mathrm{CH}_{2}$ and $\mathrm{CH}_{3}$ groups. Bands in the region $1600-1400 \mathrm{~cm}^{-1}$ corresponds to C-C stretching, confirm existence of aromatic compounds and absorption band region of $1500-1400 \mathrm{~cm}^{-1}$ shows deformation of $\mathrm{C}-\mathrm{C}$ bonds of the phenolic groups present in the studied sample of A.xanthophloea tannins.

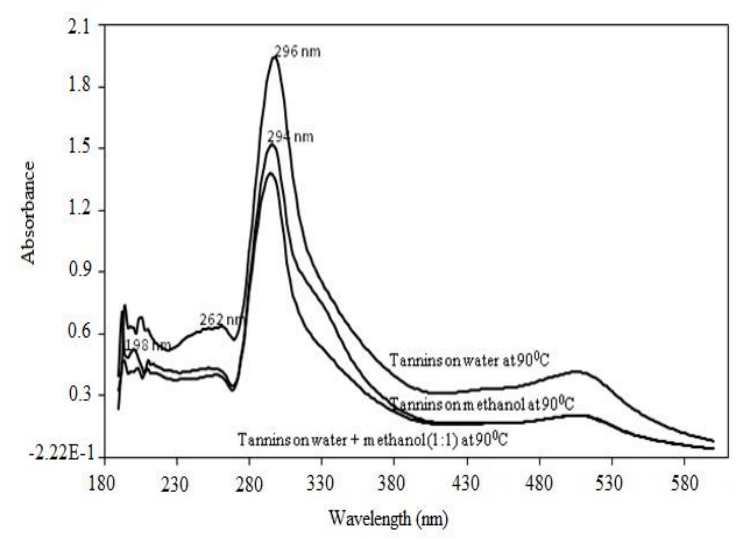

Figure 8. UV-visible spectrum of Acacia xanthophloea tannin on different solvents.

Table 4. UV spectral data of standards of polyphenols and sample A.Xanthopholoea (bark)

\begin{tabular}{|c|c|c|}
\hline \multirow[b]{2}{*}{$\begin{array}{l}\text { Tannins and } \\
\text { related phenolics }\end{array}$} & \multicolumn{2}{|c|}{ Wavelength (nm) } \\
\hline & $\begin{array}{l}\text { Ethyleneic band } \\
\left(E_{2}-\text { band }\right)\end{array}$ & $\begin{array}{l}\text { Benzoic } \\
\text { band (B - } \\
\text { band) }\end{array}$ \\
\hline Std. gallic acid & 216 & 264 \\
\hline Std. tannic acid & 220 & 280 \\
\hline Std. catechin & 208 & 280 \\
\hline Std. catechol & 216 & 276 \\
\hline $\begin{array}{l}\text { Std. m-hydroxy } \\
\text { benzoic acid }\end{array}$ & 207 & 292 \\
\hline Sample of & 250 & $252-262$ \\
\hline $\begin{array}{l}\text { A.xanthophloea } \\
\text { (bark) }\end{array}$ & & $280-296$ \\
\hline
\end{tabular}

Peak around $1320 \mathrm{~cm}^{-1}$ correspond to $\mathrm{C}-\mathrm{O}$ stretching which confirms the occurrence of alcoholic, carboxylic acid, ester and ethers [34] and peak at $1616 \mathrm{~cm}^{-1}$ represents aromatic $-\mathrm{C}-\mathrm{O}$ stretching. Aromatic $\mathrm{CH}_{2}-\mathrm{OH}\left(-\mathrm{CH}_{2}\right)$ vibration is identified by the peak appear at $1443 \mathrm{~cm}^{-1}$. IR spectrum of presently studied samples does not shows any signals of free $\mathrm{H}_{2} \mathrm{O}$ molecules owing to nearby no supportive 
bands at $2130 \mathrm{~cm}^{-1} \& 1650 \mathrm{~cm}^{-1}$ and at about $700 \mathrm{~cm}^{-1}$ [29].

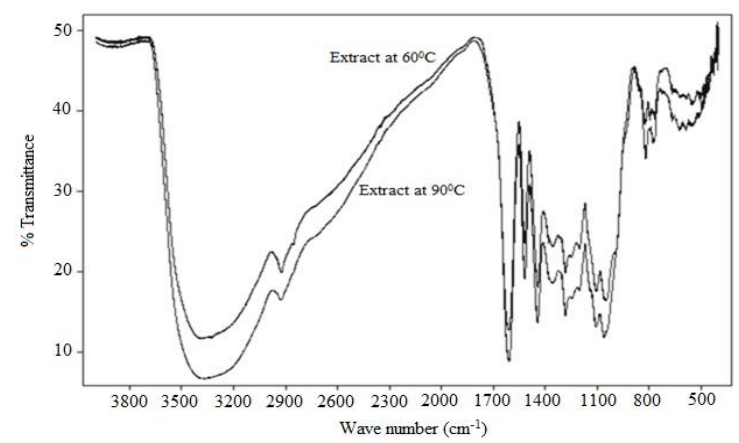

Figure 9. FTIR spectrum of Acacia xanthophloea tannins on water at $60^{\circ} \mathrm{C}$ and $90^{\circ} \mathrm{C}$

The FTIR spectrum of the study also shows that the absorption band peak values are same at all frequency bands on both tannin extracts at $60^{\circ} \mathrm{C}$ and $90^{\circ} \mathrm{C}$. The study also reveals that the greater absorption of peak band frequencies (Figure 9) of tannin extracted at $90^{\circ} \mathrm{C}$. Thus, extraction of tannins from A.xanthophloea has greater efficiency at $90^{\circ} \mathrm{C}$ on aqueous medium than lower temperatures.

FTIR analysis was also used for study on the effect of different solvents that used for the extraction of tannins from A.xanthophloea, and the corresponding spectrum is given in Figure 10.

It shows the corresponding frequency band peak values like aqueous tannin extract at $90^{\circ} \mathrm{C}$ even in methanol and it mixture with water. But, the IR band peaks of methanolic extract is very sharp in all frequency range than others and the frequency bands of methanolic tannin extract of sample has greater absorption (shown in Figure 10) that confirms the tannins and other polyphenols that extracted well on methanol than water and mixture of solvents.

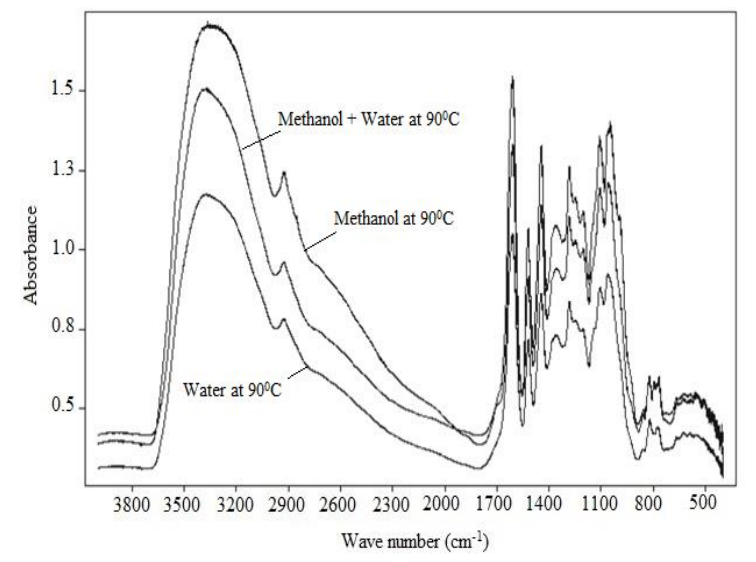

Figure 10. FTIR spectrum of Acacia xanthophloea tannins extract using different solvents.

\section{CONCLUSIONS}

The current research work spotlights the tannins extraction and characterization that obtained from Acacia xanthophloea bark. Experiments carried out and drawn the following conclusions:

Moisture content of the tannin sample estimated about $17.86 \pm 0.51 \%$. Hence the sample does contain greater amount of phytochemical especially tannins.

Methanol, water and its mixture used as solvent, among these \% yields of tannin methanolic extract has $52.55 \%$. This is due to its being organic polar solvent.

UV-visible spectroscopy of sample was carried out, results confirms the availability of tannins and flavanoid ring system. Also, this study supporting to use the water as extracting solvent for tannins from A.xanthophloea.

FTIR study reveals that the characteristic absorption peak of polyphenols in all kinds of extracts. This study also revealed greater efficiency of tannins that extracted at $90^{\circ} \mathrm{C}$ by using water as solvent. Also, methanolic extract of sample has greater absorption bands among the other solvents used for extraction of tannins.

Thus, this study confirms and recommends that the methanol and water is to use as solvent for the extraction of tannins from A.xanthophloea like other acacia species. Most of characterization of the present study favors that methanol is more appropriate solvent than water.

\section{RECOMMENDATIONS}

Results of this study established and recommending using the easy accessible and eco-friendly tanning material could probably be achieved that are available around us. For those wishing to make their own tanning solutions obtained from extraction of tannins using suitable solvents and it is a less expensive method and probably the most common methods. Alcohol, water and its mixture could be recommended as usage for extracting the tannins, which is a simple common method and best suited for A.xanthophloea tannins like species. The extracted tannins could be applied on the skin/hides to process into finished leather 
which might be advisable and useful as leather material for making of some leather goods.

\section{ACKNOWLEDGMENT}

The authors greatly acknowledged Arba Minch University and Department of Chemistry for provided the laboratory and other facilities to accomplish this research with in stipulated time.

\section{REFERENCES}

[1]. Koloka, O., Moreki, J.C. (2011). Tanning Hides and Skins Using Vegetable Tanning Agents in Hukuntsi Sub-district, Botswana. Journal of Agricultural Technology, 7(4) 915-922.

[2]. Rolland, W. (2014). Vegetable Tanning in Bolgatanga: Challenges and the Way Forward. Arts and Design Studies, Vol.16, pp.27-37.

[3]. Ramesh, D., Seguye, S., Abiyu, K.B. (2016). A Review of Bio-tanning Materials for processing of Fish Skin into Leather. International Journal of Engineering Trends and Technology, 39(1) 10-20.

[4]. Taotao, Q., XinGao., Jing, R., Xiaoke, C., Xuechuan W. (2016). A Chrome-Free and Chrome-Less Tanning System Based on the Hyper branched Polymer. American chemical Society Sustainable Chemical Engineering, Vol.4, pp.701-707. doi: 10.1021/acssuschemeng.5b00917

[5]. Mahdi, H., Palmina, K., Glavtch, I. (2006). Characterization of Acacia Nilotica as an Indigenous Tanning Material of Sudan. Journal of Tropical Forest Science, 18(3) 181-187.

https://www.jstor.org/stable/43594670

[6]. Mahdi, H., Palmina, K., Tony, C. (2013). Tannins Characterization of some Indigenous and Exotic Woody Plant Species and Two Agricultural Crops in Sudan. Journal of Forest Products \& Industries, 2(6) 38-46.

[7]. Franco, J.U., Ramesh, D., Karthikeyan M.R. (2019). A Review of Eco-Friendly Preservative and Bio-Tannin Materials Using Powdered Barks of Local Plants for the Processing of Goatskin. International Research Journal of Science and Technology, 1(1) 13-20. doi:10.46378/irjst.2019.010103
[8]. Selma, A Hussein. (2017). Utilization of Tannins Extract of Acacia seyal Bark (Taleh) in Tannage of Leather. Journal of Chemical Engineering Process Technology, 8(3) 1000334. doi: 10.4172/2157-7048.1000334

[9]. Maria, F.C., Paula, G.O., Antia, G.P., Catarina, L.L., Cecilia J.L., Miguel A.P., Jesus S.G. (2020). Review Technological Application of Tannin-Based Extracts. Molecules, 25(3) 614.

doi: 10.3390/molecules25030614

[10]. Franco, J.U., Ramesh, D., Karthikeyan, M.R. (2020). Preparation and Characterization of Eco-friendly Ash Salts for Goat Skin Preservation. International Journal of Innovative Technology and Exploring Engineering, 8 (11S) 184-190.

doi: 10.35940/ijitee.K1039.09811S19

[11]. Hylli, M., Guxho, G., Drushku, S. (2012). Determination of Some Chemical and Physico-mechanical Indicators of Albanian Leather, ZAŠTITA MATERIJALA, 53(2) 102-108. doi: UDC:615.1.017.4/.6 (497.5)

[12]. Ekaterini Malea, Stamatis C. Boyatzis, T, Marina Kehagia. (2010). Cleaning of Tanned Leather: Testing with Infra-Red Spectroscopy and SEM-EDAX, Joint interim meeting of five ICOM-CC working groups: Leather and Related materials, pp.1-12.

[13]. Alim AbdElgadir, H. A., Gurashi Abd Allah, G. E., Adil El, H.A. (2016). Utilization of Improved Indigenous Tannins of Grain Powder (Acacia Nilotica) in Eco Friendly Tannage, International Journal of Multidisciplinary and Current Research, Vol.4, pp.14-20.

[14]. Janat Akhanovna, M.B., Koffi, M.K., Bekro Y.A., Marc, G.D.Bi., Zomi Bi T.G., Mamba, V., Boua B.B. (2008). Phyto-compounds of the Extract of Four Medicinal Plants of Cote Divoire and Assessment of their Potential Antioxidant by TLC, European Journal of Scientific Research, 24(2) 219-228.

[15]. Antwis-Boasiatao, C. Animapauh, S.O. (2012). Tannin Extraction from the barks of three tropical hardwoods for the production of adhesives, Journal of 
Applied Sciences Research, 8(6) 29592965.

[16]. Senthil R., Vedakumari S.W., Hemalatha T, Sumathi V., Gobi N., Sastry T.P. (2016). New Approaches for the Effective Utilization of Fish Skin Wastes of Aluterus Monoceros. Journal of Earth Environment Health Science, Vol.2, pp.50-150.

[17]. Mohammed Alhadi Ebrahim. (2015). Leather Quality of Kabashi Desert Sheep, EC Veterinary Science, Vol.2, pp.103108.

[18]. Lokeswari, N., Peela Sujatha. (2011). Isolation of Tannins from Caesalpinia Coriaria and Effect of Physical Parameters, International Research Journal of Pharmacy, 2(2) 146-152.

[19]. Smith, N. (2008). Field Guide to the Acacia of South Arica, Briza Publications Pretoria, p.1.

[20]. Nundkumar, N., Ojewole, J.A.O. (2002). Studies on the Antiplasmodial Properties of Some South African Medicinal Plant used and Antimalarial Remedies in Zulu Folk Medicine, Meth Find Exp Clin Pharmacol, 24(7) 397-401.

[21]. Donlop, R.W. (2005). Acacia Mearnsli De wild In: Jansen, P.C.M and Cardon, D.Editors (Procter J: Dyes and Tannins/Colorants), PROTA, Wagenigen, Netherland.

[22]. Haroun, M., Plamina,K., Corington, T. (2013). Analysis of Commercial Vegetable Tannins Material and Related Polyphenols of Selected Acacia Species in Sudan, Journal of Forest and Industries, 2(1) 21-28.

[23]. Isam Eldin Hussein Elgailani and Christina YacoubIshak. (2016). Methods for Extraction and Characterization of Tannins from Some Acacia Species of Sudan, Pakistan Journal of Analytical and Environmental Chemistry, 17(1) 4349.

doi: $10.21743 / \mathrm{pjaec} / 2016.06 .007$

[24]. Hong-xia, L., Su-qin,S., Guang-hua, Lv., Kelvin, K.C.Chan. (2006). Study on Angelica and its Different Extracts by Fourier Transform Infrared Spectroscopy and Two-dimensional Correlation IR Spectroscopy, Spectrochimica Acta. Part

\author{
A:Molecular and Biomolecular \\ Spectroscopy, 64(2) 321-326. \\ doi: 10.1016/j.saa.2005.07.026
}

[25]. Kajdzanoska M., Gjamovski V., Stefova M. (2010). Identification of Phenolic Compounds in Cultivated Strawberries from Macedonia, Macedonian Journal of Chemical Engineering, 29(2) 181-194.

[26]. Sisa M., Bonnet S.L., Ferreira D., Vander Westhuzen J.H. (2010). Phytochemistry of Flavonoids, Molecules, 15(8) 51965245 .

doi: 10.3390/molecules15085196

[27]. Stuart, B. H. (2005). Experimental Methods in Infrared Spectroscopy: Fundamentals and Applications", John Wiley \& Sons, Ltd, Chichester, UK, pp.76-77.

[28]. Deepa, S., Sripriya, N., Bangaru, C. (2014). Studies on the Phytochemistry, Spectroscopic Characterization and Antibacterial Efficacy of Salicornia Brachiata, International Journal of Pharmacy and Pharmaceutical Sciences, 4(6) 430-432. 